\title{
Public response to the 2014 chemical spill in West Virginia: knowledge, opinions and behaviours
}

\author{
Elena Savoia ${ }^{*}$, Michael A. Stoto ${ }^{2}$, Rahul Gupta ${ }^{3}$, Nasandra Wright $^{4}$ and Kasisomayajula Viswanath ${ }^{5}$
}

\begin{abstract}
Background: On January $9^{\text {th }}$ 2014, a faulty storage tank leaked 10,000 gal of an industrial coal processing liquid into the Elk River in West Virginia (WV), contaminating the drinking water of the nine counties collectively known as the Kanawha Valley. The aim of this study was to 1) explore how and when people obtained information about the water contamination and 2) understand how individual and social factors such as socio-demographic characteristics, timing of information, trust in government, and risk perception influenced compliance with recommended behaviours and the public's views on the need for environmental regulations.
\end{abstract}

Methods: Between February 7-26, 2014, a survey was conducted of adult residents of West Virginia including geographic areas affected and non-affected by the chemical spill. The total population-based sample size was 690 and the survey was administered online. Descriptive statistics and multivariate statistical models were created to determine what factors influenced compliance and public opinions.

Results: Findings from this study show that, during the 2014 West Virginia water crisis, information about water contamination spread quickly, as $73 \%$ of survey respondents across the state and $89 \%$ within the affected counties reported they heard about the incident the same day it occurred. Most people received the information promptly, understood what happened, and understood what to do to prevent exposure to the contaminant. The majority of respondents living in affected counties (70 \%) followed the recommended behaviours. Among participants who voiced an opinion on the role of government in environmental regulations, the majority of respondents (54 \%) reported there is "too little regulation."

Conclusion: Data from this study show that a higher perception of risk and timely receipt of information are associated with compliance with recommended behaviours, underlying the importance of releasing information to the public as quickly as possible during a crisis. This study also highlights the importance of coordinating risk communication activities beyond the area of the incident to assure public understanding of what measures are recommended, which are not and where.

\section{Background}

On January $9^{\text {th }} 2014$, a faulty storage tank leaked 10,000 gal of an industrial coal processing liquid into the Elk River in West Virginia (WV); the leak occurred upstream the main source of water for the company serving drinking water to the residents of nine counties collectively known as the Kanawha Valley. In the United States, chemicals have rarely

\footnotetext{
* Correspondence: esavoia@hsph.harvard.edu

'Department of Biostatistics and Division of Policy Translation and Leadership Development, Harvard T.H. Chan School of Public Health, 401 Park Drive, Boston 02115, MA, USA

Full list of author information is available at the end of the article
}

been associated with waterborne disease outbreaks, for this reason the West Virginia water crisis can be described as a unique and interesting incident [1]. The January 2014 chemical contamination of the Elk River in West Virginia (WV) disrupted public water supply to thousands of homes, caused the closure of schools and businesses, and as a result, hundreds of people reported symptoms they associated with exposure to the contaminated water.

On January $9^{\text {th }}$, during the course of the day, state and local officials received several complaints of a licorice odor in the air and taste in the water due to the presence of the chemical [2-4]. At $6 \mathrm{pm}$ the day of the leak, Governor 
Earl Ray Tomblin appeared on television and issued a "Do Not Use" order that was unprecedented in scale or scope. As a result, approximately 300,000 residents (16\% of the population of West Virginia), living in the nine counties affected by the spill, were told that their tap water was not safe for "drinking cooking, washing, or bathing" and to be aware of signs and symptoms of exposure to the chemical such as rashes, nausea, vomiting, and wheezing [5]. Besides local television news, state and local officials used many other channels of communication, including radio, social media and town halls. A description of the timeline of the response and specific challenges experienced by the responders in coordinating communication efforts have been described elsewhere [6].

At the time of the incident, very little toxicological information was available on the main chemical contained in the liquid: 4 -methylcyclohexane methanol (crude MCHM). According to the producer, MCHM is harmful if swallowed, causes skin and eye irritation, and at elevated temperatures can cause irritation of the eyes and respiratory tract [7]. Potential carcinogenic effects were investigated after the incident showing DNA damage and need for further carcinogenic evaluations [8].

In the week following the spill the water distribution system was flushed and residents of the affected areas were advised to flush their plumbing systems using a stepwise protocol [9]. However, after the "Do Not Use" order was lifted the odor remained and questions about the health effects of MCHM persisted [6].

The cultural, political, and economic context of the Kanawha Valley created a unique case in which to study the population's exposure to information, their knowledge, behaviours and reactions to this emergency. For nearly a century, the Kanawha Valley has been home to the largest concentration of chemical plants in the United States [10]. Valley residents are not unfamiliar with the risk of chemical spills, environmental agencies receive several calls on a weekly basis on potential spills from industries working in the area, [6] but in this circumstance little was known about the health risks of the chemical product that spilled in the water and the persistent odor and taste generated concern in the population. For decades, residents in the valley have participated in long running debates over environmental oversight of the coal and chemical industries, the foundation of West Virginia's economy.

In times of low risk as well as in times of emergencies, in West Virginia as well as in any other area, information about the potential threat of chemicals or pollutants circulates widely from both official and unofficial sources and exposure to circulating information may influence or not behaviours [11]. Under conditions of uncertainty on the extent of exposure to a particular product and its impact on health, risk communication becomes a challenging dynamic process [12] in which the public has a myriad of opportunities to seek, assimilate, and act or do not act on the information received and to accept or contest official opinion and advice [13]. More specifically, during large scale emergencies, several studies have shown that risk communication may fail to reach intended communities particularly those most at risk [11-17].

The aim of this study is to 1) explore how and when people obtained information about the water contamination and 2) understand how individual and social factors such as socio-demographic characteristics, timing of information, trust in government, and risk perception influenced compliance with recommended behaviours and the public's views on the need for environmental regulations.

\section{Methods}

Between February 7-26, 2014, a survey was conducted of adult residents of West Virginia including geographic areas affected and non-affected by the chemical spill. The total population-based sample size was 690; 145 respondents were drawn from the local sample of Knowledge Networks' KnowledgePanel ${ }^{\circ}$, a survey system with an address-based sample frame that provides non-Internet capable households with a laptop computer and free Internet access. The remaining participants (545) were recruited solely for the purpose of this survey (opt-in-panel), using the KnowledgePanel calibration technique [17] with an over-sample of residents of low socio-economic position (SEP). Base weights and panel post-stratification weights were included with the sampling technique. We sought to oversample individuals with low SEP so we would have a large enough sample to identify potential barriers in receiving and understanding public health messages due to low literacy levels and/or limited access to some channels of communication. Participants were eligible to win prizes drawn through monthly sweepstakes.

\section{Survey design}

The questions for this survey were adapted from a survey implemented in the aftermath of the 2010 Boston Water Crisis [18] and from polls conducted by Gallup ${ }^{\circ}$ [19]. The survey covered knowledge and adoption of preventive behaviours, perception of risk, use of information channels, and the public's views and reactions on the role of government. Pilot testing of the survey was conducted on 45 individuals prior to its fielding. The study was approved by the Harvard T.H. Chan Institutional Review Board (IRB).

\section{Measures}

\section{Independent variables}

Independent variables were originally selected on the basis of substantive and theoretical relevance in accordance with the "Structural Influence Model of Communication in Public Health Emergency Preparedness" [11-16, 18]. 
This heuristic model focuses on the role of communication in explaining the relationship between social determinants and health outcomes, and has been successfully used to examine communications during the 2010 Boston water crisis [18]. Six types of independent variables were included: area of residence (living or not in one of the affected counties), ${ }^{1}$ social determinants (education, income, savings), perceived risk, trust in government, whether and when the respondent learned about the emergency and demographic variables (gender, age). More details on how each variable was defined and categorized are provided in Table 1.

\section{Dependent variables}

A scoring system was devised to create two dependent variables: 1) compliance with recommended behaviours and 2) views on government's role and priorities. To measure compliance with recommended behaviours, responses to the following question were analyzed: In response to news reports of the water crisis, did you do any of the following? The response options included recommended and, non-recommended behaviours listed in Table 1. Based on these responses we created a count variable ranging from 0 (did not follow any recommended behaviour, followed a non- recommended behaviour or

Table 1 Definition of variables

Age
Education
Household income in the past 12 months
Savings - If you lost your current source of income (your paycheck, public
assistance, or other forms of income) how long could you continue to live at
your current address and standard of living?
Timeliness of information - When did you first learn about the water crisis?

Perceived risk -To the best of your knowledge, how likely was it for someone who lived in the affected areas to get sick by drinking tap water during the water crisis?

Trust in government -Would you say that the government generally is?

Knowledge of recommended behaviors -To the best of your knowledge what actions were recommended in the areas affected by the water crisis? This question had correct response options describing recommended behaviors (e.g. drinking bottled water, avoiding drinking tap water, avoiding taking showers or bathing with tap water, avoiding using tap water to prepare baby formula) and non-correct options recommended behaviors (e.g. drinking water only after boiling it, drinking filtered tap water, cooking with boiled or disinfected water, washing dishes with boiled or disinfected water and brushing teeth with boiled or disinfected water).

Behavioral Compliance a) $18-29$, b) $30-44$, c) $45-59$ and d) $\geq 60$

a) < high school, b) high school, c) some college and d) bachelor degree or higher

a) $\leq \$ 14,999$, b) $\$ 15,000-\$ 34,999$, c) $\$ 35,000-\$ 59,999$, d) $\$ 60,000-\$ 99,999$ and e) $\geq \$ 100,000$.

a) $0=$ less than 2 months, b) $1=3$ months-one year and c) $2=$ more than one year.

a) $1=$ the same day the water contamination was reported (Thursday January 9) = 1 b) one or more days after $=0$.

a) $0=$ very unlikely or unlikely, b) $1=$ somewhat likely and c) $2=$ very likely.

a) $0=$ run by few people looking for their own interests and b) $1=$ run for the benefit of all.

a) $1=$ the respondent checked at least one recommended behavior and did not check any non-recommended behavior b) $0=$ the respondent did not check any of the recommended behaviors or checked at least one non-recommended behavior.
a)Recommended behaviors (e.g. drank only bottled water, cooked with only bottled water, washed dishes with only bottled water, brushed teeth with only bottled water, avoided taking showers or bathing with tap water, avoided tap water from coming in contact with skin, avoided using tap water for washing clothes),

b)Non-recommended behaviors (e.g. drank water after boiling it, cooked with only boiled or disinfected water, washed dishes with only boiled or disinfected water, brushed teeth only with boiled or disinfected water), and

c)Non-recommended behaviors geographically specific to affected counties (drank tap water and followed no recommended behavior).

$1=$ the respondent checked at least one recommended behavior and did not check any non-recommended behavior or $0=$ the respondent did not check any of the recommended behaviors or checked at least one non-recommended behavior.

Flushing compliance: After learning the water crisis was over, did you flush a) cold water faucets for at least 5 min?, b) warm water faucets for at least 15 min?, c) appliances (i.e. ice maker, dish washer). Answer options to this question were Yes/No. 
followed a combination of recommended and not recommended behaviours) to 1-7 (maximum number of recommended behaviours).

Once the water was determined to be appropriate for use, people in the affected counties were recommended to flush faucets and appliances to eliminate any residual contaminants. Compliance with this procedure was assessed through responses to three questions as described in Table 1.

To measure opinion on government's role and priorities, two variables were generated using data from the following questions: 1) In general do you think there is too much, too little, or about the right amount of government regulation on the environment? and 2) Do you think it should be a high, medium or low priority for the government to regulate the way major chemical and coal industries do business or the government should not address this issue? Separate ordinal variables were created where responses were coded as $0=$ too much, $1=$ right amount and $2=$ too little and $0=$ government should not address this issue or it should be a low priority, $1=$ a medium priority and $2=$ a high priority.

\section{Statistical analyses}

Study specific post stratification weights based on gender, age, metropolitan area, race/ethnicity, education and income were created using the most recent Census Bureau Current Population Survey to adjust for noncoverage and non-response biases. Descriptive statistics were calculated showing the frequency of both the dependent and independent variables. For count variables, negative binomial regression was used in bivariate and multivariate models after rejecting the hypothesis of equivalence in the mean and variance of the count. For ordinal variables, ordered logistic regression was applied using Stata's ologit command and the parallel regression assumption was tested by means of the Brant test when needed. In all analyses study specific weights were included to test for bivariate associations between each predictor and the two dependent variables. A $P$-value of $\leq 0.25$ was used as a cut-off to include the variables in the model. In doing so, the following variables were dropped from the multivariate analysis of compliance: age, gender, education, savings, and trust in government. For the analysis of opinions on the role of government in regulating the environment the following variables were dropped: education and savings. Interactions were tested between area of residence (within or outside the nine affected counties) and the two following variables: timeliness of information and knowledge of recommended behaviours. Analyses were performed using Stata statistical software, release 13, College Station, TX.

\section{Results}

\section{Sample characteristics}

The overall response rate was $86 \%$, with 592 individuals of the 690 sampled beginning the survey. Of these, 464 (67\% of the original sample) completed the entire survey, and their responses were included in the final analyses. Of the 464 respondents, 129 (27.8\%) lived in one of the nine counties affected by the crisis, while the remaining 335 (72.1\%) lived in West Virginia but outside the affected counties. Data from respondents from all counties were analyzed and differences were investigated between respondents from the affected areas and the rest of the state. The proportion of respondents living in the affected counties did not vary between the KnowledgePanel ${ }^{\circ}$ and opt-in panel subsamples (27\% versus $28 \%$ ). Socio-demographic characteristics of those living in and outside the affected counties are shown in Table 2. The raw data (before weighting) show that the subsample of people living in the affected counties have a higher level of education compared to those living outside this area, but between the two groups there were no statistically significant differences in any of the socio-demographic variables including education. Despite intentional oversampling in the opt-in sample, when the sample characteristics were compared to the Census data our sample was found to underrepresent the category of educational level "less than high school."

\section{Risk perception}

Fifty-six percent of respondents reported that "getting sick from drinking tap water" was very likely, with no difference between those living in the affected counties and those living outside this area (50\% and $58 \%$ respectively Binomial $P$-value $>0.05$ ). Respondents who reported a household income greater than $\$ 100,000$ were the least likely to think that drinking tap water would cause sickness when compared to respondents in lower income categories. For example, those reporting an income of $<\$ 15,000$ were twice as likely to report drinking water as risky compared to those with an income of $>\$ 100,000(\mathrm{OR}=2.37,95 \%$ C.I. 1.07-5.22). Similarly, respondents who reported they could not afford their current standard of living for more than two months if income was lost were almost twice as likely $(\mathrm{OR}=1.9,95 \%$ C.I. $1.3-3.05)$ to think that drinking the water would cause sickness compared to respondents that could afford their standard of living for over a year. Most of the respondents (56\%) agreed or strongly agreed with the following statement: "Chemical or oil spills in the water are happening all the time every day".

\section{Timeliness of information}

Seventy-three percent of respondents answered that they heard about the water crisis on the same day the water 
Table 2 Sample characteristics versus U.S. Census Bureau (American Community Survey 2009-2013)

\begin{tabular}{|c|c|c|c|c|c|c|}
\hline Variable & Total sample n (\%) & Census & $\begin{array}{l}\text { Living in the affected } \\
\text { counties } \mathrm{n}(\%)\end{array}$ & Census & $\begin{array}{l}\text { Living outside the affected } \\
\text { counties } n(\%)\end{array}$ & Census \\
\hline \multicolumn{7}{|l|}{ Gender $(n=464)$} \\
\hline Male & $220(47.4)$ & $49 \%$ & $58(44.6)$ & $49 \%$ & $161(48.3)$ & $49 \%$ \\
\hline Female & $244(52.6)$ & $51 \%$ & $71(55.4)$ & $51 \%$ & $173(51.7)$ & $51 \%$ \\
\hline \multicolumn{7}{|l|}{ Age $(n=463)$} \\
\hline $18-24$ & $29(6.3)$ & $6 \%[20-24]$ & $9(7.0)$ & $6 \%[20-24]$ & $20(6.0)$ & $7 \%[20-24]$ \\
\hline $25-34$ & $69(14.9)$ & $12 \%$ & $17(13.2)$ & $12 \%$ & $52(15.5)$ & $12 \%$ \\
\hline $35-44$ & $63(13.6)$ & $13 \%$ & $22(17.1)$ & $13 \%$ & $41(12.3)$ & $13 \%$ \\
\hline $45-54$ & $106(22.8)$ & $15 \%$ & $27(20.9)$ & $15 \%$ & $79(23.7)$ & $15 \%$ \\
\hline $55-64$ & $129(27.8)$ & $14 \%$ & $36(27.9)$ & $8 \%$ & $93(27.8)$ & $17 \%$ \\
\hline $65-74$ & $57(12.3)$ & $9 \%$ & $17(13.1)$ & $16 \%$ & $40(12.0)$ & $7 \%$ \\
\hline $75+$ & $10(2.2)$ & $7 \%$ & $1(0.8)$ & $7 \%$ & $9(2.7)$ & $7 \%$ \\
\hline \multicolumn{7}{|l|}{ Education } \\
\hline$(n=463)$ & $33(7.2)$ & $17 \%$ & $7(5.2)$ & $16 \%$ & $26(7.9)$ & $17 \%$ \\
\hline$<$ High school & $221(47.7)$ & $41 \%$ & $47(36.4)$ & $39 \%$ & $172(51.5)$ & $42 \%$ \\
\hline High school & $104(22.5)$ & $24 \%$ & $38(29.6)$ & $25 \%$ & $67(20.1)$ & $24 \%$ \\
\hline $\begin{array}{l}\text { Some college } \\
\text { Bachelor or more }\end{array}$ & $105(22.6)$ & $18 \%$ & $37(28.8)$ & $20 \%$ & $69(20.5)$ & $17 \%$ \\
\hline \multicolumn{7}{|l|}{ Income $(n=450)$} \\
\hline$<\$ 10,000$ & $26(5.6)$ & $10 \%$ & $7(5.4)$ & $10 \%$ & $19(5.9)$ & $10 \%$ \\
\hline$\$ 10,000-\$ 24,999$ & $48(10.4)$ & $22 \%$ & $19(14.7)$ & $23 \%$ & $29(9.0)$ & $22 \%$ \\
\hline$\$ 25,000-\$ 49.999$ & $124(26.7)$ & $27 \%$ & $29(22.5)$ & $28 \%$ & $95(29.3)$ & $26 \%$ \\
\hline$\$ 50,000-\$ 74.999$ & $98(21.1)$ & $18 \%$ & $25(19.4)$ & $12 \%$ & $73(22.5)$ & $20 \%$ \\
\hline$\$ 75,000-\$ 99.999$ & $82(17.7)$ & $10 \%$ & $22(17.1)$ & $12 \%$ & $60(18.5)$ & $10 \%$ \\
\hline$\$ 100,000-\$ 199,999$ & $63(13.6)[\$ 100,000-\$ 174,999]$ & $11 \%$ & $21(16.3)[\$ 100,000-\$ 174,999]$ & $12 \%$ & $42(13.0)[\$ 100,000-\$ 174,999]$ & $10 \%$ \\
\hline$>\$ 200,000$ & $9(1.9)$ & $2 \%$ & $3(2.3)$ & $3 \%$ & $6(1.8)$ & $2 \%$ \\
\hline
\end{tabular}

contamination was reported (January 9). The cumulative percentages of those who heard about the crisis rose to $93 \%$ by January 10 , and $100 \%$ by January 12 . People living in the affected counties were 3.7 times more likely to have heard the news on the day the spill occurred compared to people living outside this area [OR $=3.795 \%$ C.I. 1.9-7.2].

\section{Source of information}

Independently of when they received the news, most people $(70 \%)$ first heard about the spill from local TV. The Internet, family, friends and co-workers were the sources of information more frequently reported as first source the news was heard from. See Fig. 1 for a description of source of information by date the information was received.

\section{Trust in government}

When asked the question "Would you say that the government generally is ...?” $77 \%$ of respondents agreed with the statement "Run by few people looking for their own interests." This percentage ranged from $86 \%$ for those living in the affected counties to $75 \%$ for those living outside this area; $14 \%$ agreed with the statement "Run for the benefit of all" (10\% in the affected counties and $16 \%$ outside this area) and $8 \%$ checked the option "Other, please specify". Among this $8 \%$, the majority (65\%) reported a negative comment denoting a lack of trust, such as "Run for the benefit of large lobby groups" or "ineffective," while $22 \%$ reported mixed opinions such as "half and half" or "not all one category," and $13 \%$ were unsure. Trust in government was subsequently used as an independent variable in the multivariate models.

\section{Knowledge of recommended behaviours}

The percentage of respondents who did not know about any recommended behaviour was low among residents of the nine affected counties; $89 \%$ of them were able to report at least one recommended behaviour. In terms of non-recommended behaviours, "washing dishes with boiled or disinfected water" was the most frequently 


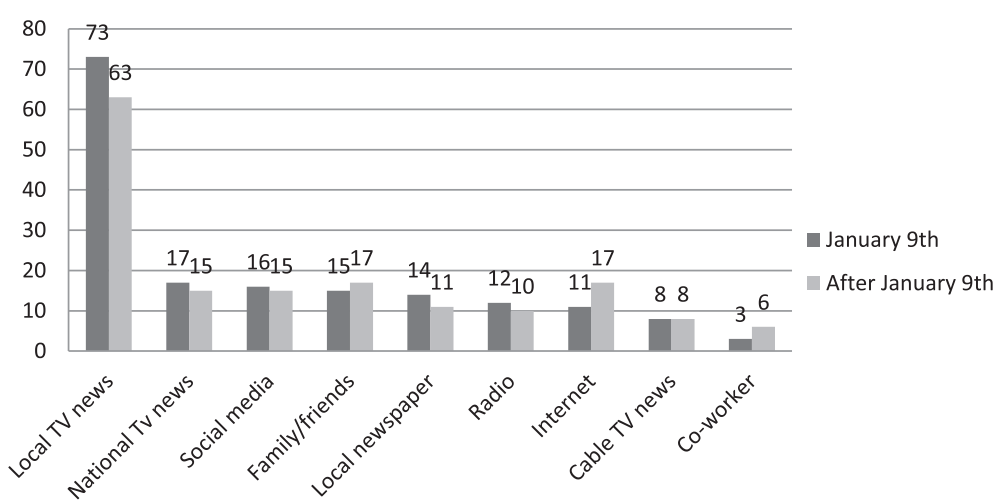

Fig. 1 Percentage of respondents hearing about the water crisis: first source of information and date

reported, with $9 \%$ of residents in the affected counties and $20 \%$ of residents in the non-affected counties reporting it as a beneficial action. Other behaviours incorrectly identified as "recommended" include: brushing teeth with boiled or disinfected water (7\% affected and $18 \%$ non-affected counties), cooking with boiled or disinfected water $(6 \%$ affected and $17 \%$ non-affected counties), and drinking water after boiling it (2\% affected and $4 \%$ non-affected counties). Knowledge of recommended behaviours was not associated with any of the socio-demographic factors, area of residence, or any other independent variables listed above.

\section{Compliance with recommended behaviours}

The main recommendation was to abstain from drinking tap water, and $69 \%$ of respondents living in the affected counties complied. There was a positive association between compliance with this recommended behaviour and perception of risk, measured as the belief that drinking the tap water will cause sickness [Pearson chisquared $p$-value $=0.02$ ]. Overall, $74 \%$ of respondents living in the affected counties were compliant with at least one preventive measure. People living in an affected county were 5.7 times more likely to follow a recommended behaviour than those living outside this area [95 \% C.I. 3.8-8.6]. Interestingly, outside the affected counties $22 \%$ of respondents followed at least one of the recommended measures, even though not necessary. Residents who received information the same day the emergency occurred were 2.3 times more likely to follow a recommended behaviour $[\mathrm{OR}=2.395 \%$ C.I. 1.2-4.5]. Similarly, people reporting a belief that drinking tap water in the affected areas was very likely to cause sickness were 2.4 times more likely to follow a recommended behaviour $[\mathrm{OR}=2.495 \%$ C.I. 1.1-5] when compared to those who thought that it was unlikely or very unlikely to make people sick. See Table 3.

In the affected counties, the recommended procedure to flush cold water faucets for $5 \mathrm{~min}$ was followed by

Table 3 Determinants of behavioral compliance

\begin{tabular}{|c|c|c|c|c|}
\hline \multirow[t]{2}{*}{ Independent Variables } & \multirow{2}{*}{$\begin{array}{l}\text { Single Predictors Models } \\
\text { IRR ( } 95 \% \text { C.I.) }\end{array}$} & \multicolumn{3}{|c|}{ Ordinal Logistic Regression Models } \\
\hline & & Model 1 & Model 2 & Model 3 \\
\hline Living in the affected counties & $5.8[3.9-8.5]$ & $6[4-9]$ & $6[4-9.2]$ & $5.7[3.8-8.6]$ \\
\hline \multicolumn{5}{|l|}{ Income } \\
\hline$\$ 15,000-\$ 34,999$ vs $<\$ 15,000$ & $0.7[0.3-1.1]$ & $0.8[0.3-1.9]$ & $0.8[0.4-1.7]$ & $0.8[0.4-1.6]$ \\
\hline$\$ 35,000-\$ 59,999$ vs $<\$ 15,000$ & $0.6[0.3-1.1]$ & $0.5[0.2-1.2]$ & $0.6[0.3-1.3]$ & $0.6[0.3-1.4]$ \\
\hline$\$ 60,000-\$ 100,000$ vs $<\$ 15,000$ & $0.8[0.4-1.4]$ & $0.7[0.3-1.5]$ & $0.8[0.3-1.7]$ & $0.8[0.4-1.7]$ \\
\hline$>\$ 100,000$ vs $<\$ 15,000$ & $0.6[0.3-1.2]$ & $0.4[0.2-1.1]$ & $0.5[0.2-1.3]$ & $0.5[0.2-1.2]$ \\
\hline Timing of information & $2.8[1.4-5.5]$ & & $2.3[1.2-4.6]$ & $2.3[1.2-4.5]$ \\
\hline \multicolumn{5}{|l|}{ Risk perception } \\
\hline -Somewhat likely versus unlikely or very unlikely & $1.3[0.7-2.5]$ & & $1.1[0.5-2.5]$ & $1.2[0.5-2.5]$ \\
\hline -Very likely versus unlikely or very unlikely & $2[1.1-3.7]$ & & $2.3[1.1-4.8]$ & $2.4[1.1-5]$ \\
\hline Knowledge of recommended behaviors & & & & $1.8[1-3.2]$ \\
\hline
\end{tabular}


$86 \%$ of respondents, flushing warm water faucets by $68 \%$, and flushing appliances by $90 \%$. Outside the affected areas, $14 \%$ of respondents flushed their cold and warm water faucets and $37 \%$ flushed their appliances.

\section{Views on government's role and priorities}

Among participants who voiced an opinion on the role of government in regulating the environment (82\%), the majority of them (54\%) reported there is "too little regulation." This percentage was much higher among those living in the affected counties (74\%) compared to those living outside this area (48\%). Twenty percent of all respondents reported that the amount of regulation is adequate (11\% in affected counties and $26 \%$ outside), and $23 \%$ said there is too much regulation (15\% in affected counties and $26 \%$ outside).

The multivariate analysis (Table 4) shows that respondents in the affected counties were 2.6 times more likely [OR $=2.695 \%$ C.I. $1.5-4.5]$ to think that there is too little government regulation when compared to respondents living outside this area. Gender was also associated with this opinion, with women being 1.9 times more likely [OR $=1.995 \%$ C.I. 1.2-2.9] to think there is too little regulation when compared to men. Similarly, higher risk perception was associated with this opinion. People reporting the highest category of risk perception (very likely to get sick if drinking tap water) in the affected areas were 2.4 times more likely [OR $=2.4$ $95 \%$ C.I. 1.2-5.1] to think there is too little regulation compared to those that believed it was unlikely or very unlikely they would get sick from drinking the tap water.
When respondents were asked their opinion on whether regulating major chemical and coal industries should be a high, medium, or low priority for government, the majority $(55 \%)$ reported that it should be a high priority, $31 \%$ reported it should be a medium priority, $6 \%$ a low priority and $7 \%$ that the government should not address this issue. Finally, respondents were asked how much they agreed or disagreed with the following statement "In this region chemical or oil spills are an acceptable compromise to have a job". The majority $(57 \%)$ reported they disagreed or strongly disagreed with this statement independently of their area of residence.

\section{Discussion}

Findings from this study show that, during the 2014 West Virginia water crisis, information about water contamination spread quickly, as $73 \%$ of survey respondents across the state and $89 \%$ within the affected counties reported they heard about the incident the same day it occurred. Most people received the information promptly, understood what happened, and understood what to do to prevent exposure to the contaminant. The majority of respondents living in the affected counties (694 \%) were compliant with the main recommendation of abstaining from drinking the tap water. Thirty-seven percent living outside this area also avoided drinking the tap water during the crisis even if not recommended, one possibility explaining this action could be a belief that the contaminant will eventually reach the water supply of other communities and highlight a need for coordinating risk communication activities beyond solely affected areas.

Table 4 Determinants of opinion on the existing amount of government regulations on the environment (too little, right amount, too much)

\begin{tabular}{|c|c|c|c|c|}
\hline \multirow[t]{2}{*}{ Independent Variables } & \multirow{2}{*}{$\begin{array}{l}\text { Single Predictor Models } \\
\text { OR (95\% C.I.) }\end{array}$} & \multicolumn{3}{|c|}{ Multiple Negative Binomial Regression Models } \\
\hline & & Model 1 & Model 2 & Model 3 \\
\hline Living in the affected counties & $3.4[1.5-5]$ & $2.8[1.7-4.6]$ & $2.9[1.7-4.7]$ & $2.6[1.5-4.5]$ \\
\hline Gender & $1.8[1.1-2.9]$ & $1.9[1.2-2.9]$ & $1.8[1.2-2.9]$ & $1.9[1.2-2.9]$ \\
\hline \multicolumn{5}{|l|}{ Income } \\
\hline$\$ 15,000-\$ 34,999$ vs $<\$ 15,000$ & $0.3[0.2-1.6]$ & $0.5[0.2-1.3]$ & $0.4[0.2-1.1]$ & $0.4[0.2-1.1]$ \\
\hline$\$ 35,000-\$ 59,999$ vs $<\$ 15,000$ & $0.6[0.3-1.5]$ & $0.8[0.3-1.8]$ & $0.7[0.3-1.6]$ & $0.7[0.3-1.6]$ \\
\hline$\$ 60,000-\$ 100,000$ vs $<\$ 15,000$ & $0.5[0.2-1.3]$ & $0.6[0.3-1.4]$ & $0.6[0.2-1.3]$ & $0.5[0.2-1.2]$ \\
\hline$>\$ 100,000$ vs $<\$ 15,000$ & $0.4[0.2-1.1]$ & $0.4[0.2-1]$ & $0.4[0.2-1]$ & $0.4[0.2-1.1]$ \\
\hline Timing of information & $0.7[0.4-1.2]$ & & $0.7[0.4-1.2]$ & $0.8[0.5-1.3]$ \\
\hline \multicolumn{5}{|l|}{ Risk perception } \\
\hline -Somewhat likely versus unlikely or very unlikely & $2.7[1.2-6.1]$ & & $1.8[0.9-3.6]$ & $1.9[0.9-4.2]$ \\
\hline -Very likely versus unlikely or very unlikely & $2.4[1.1-5]$ & & $2.1[1-4.2]$ & $2.4[1.2-5.1]$ \\
\hline Trust in government & $0.7[0.4-1.1]$ & & & $0.8[0.5-1.4]$ \\
\hline Knowledge of recommended behaviors & $1.1[0.7-1.8]$ & & & $1[0.6-1.6]$ \\
\hline
\end{tabular}


Respondents in the affected counties learned about the crisis sooner and were more likely to follow the recommended behaviours. In contrast, those in the nonaffected counties, more frequently erroneously believed that boiling or disinfecting the water was a recommended behaviour. Respondents in the non-affected areas (who were not exposed to the contaminated water), on the other hand, were almost as likely as those in the affected areas to believe that getting sick from drinking the water was very likely. This suggests that risk communication efforts worked reasonably well for the affected population, but caused confusion in other parts of the state.

Data from this study clearly show that a higher perception of risk and timely receipt of information are associated with compliance with recommended behaviours, underlying the importance of releasing information to the public as quickly as possible during a crisis. In contrast to previous studies we did not find a difference in compliance across socioeconomic levels [20-24]. Our results on the association between risk perception and compliance are consisted with previous studies referring to "Protection Motivation Theory" (PMT) as a potentially useful framework for understanding public response or intention to respond to recommended health behaviours [25]. In our study we emphasize the importance of observing actual behaviours after a crisis and to include in such observations factors related to the response of the public health system (i.e. time of release of information to the public) to contextualize and better explain public behaviours and inform the response to future crisis. During this event, proactive public health strategies and a saturation of media coverage likely resulted in a wide diffusion of information, a study on the relationship between the use of specific channels of information by the public and timing of the receipt of information was beyond the purpose of this paper.

Furthermore, the literature describes trust and credibility as critical components of effective risk communication [26-30]. In this study we limited our observation of "trust" to generic questions on "trust in government" which resulted not to be associated with compliance with recommended behaviours or opinions on the role of government in regulating the environment. We recognize that trust is a complex construct and that our study does not adequately describe such construct. However, this crisis seems to have exceeded the public's tolerance for lack of government oversight on environmental regulations. The fact that we found a difference in such opinions between residents in the affected versus nonaffected counties support our hypothesis that the experience of the incident influenced their opinion on the need for regulations; as shown by $74 \%$ of survey respondents, living in the affected areas, reporting that there is "too little ... government regulation" on the environment, a view also found to be disproportionately held by women and those with a high perception of risk. Such findings may be of potential interest to the policy maker.

The main limitation of this study was an underrepresentation of respondents of low socio-economic position and low educational level, which might have limited our ability to describe behaviours and opinions among this group. However all statistical analysis took socio-demographics into consideration, by including study specific post-stratification weights.

The use of a cross sectional study limited the ability to determine public opinions and behaviours prior to the emergency. However the fact that respondents living in the affected counties were more likely to have an opinion on the need for regulations suggests that the experience of living through the emergency influenced such opinion. That is, the proximity of the threat influenced their risk perceptions, and subsequent behaviours.

\section{Conclusion}

Findings from this study show that during a crisis communicating to the public in a timely manner affects compliance with recommended behaviours, and that risk-perceptions are associated with compliance. This study also highlights the importance of coordinating risk communication activities beyond the area of the incident to assure public understanding of what measures are recommended, which are not and where. Finally, results may be of interest to the policy maker in light of the finding that people that experienced the crisis had stronger opinions on the role of government in regulating the environment compared to those living in non-affected areas.

\section{Endnotes}

${ }^{1}$ Boone, Cabell, Clay, Jackson, Kanawha [which includes the city of Charleston], Lincoln, Logan, Putnam or Roane.

\section{Abbreviation \\ MCHM: 4 -methylcyclohexane methanol.}

\section{Competing interests}

The authors declare that they have no competing interests.

\section{Authors' contributions}

ES conceptualized the study and analyzed the data, MS provided support in the development of the survey questions and interpretation of the statistical findings, NW provided support in the interpretation of finding and development of the discussion, RG provided support in the interpretation of findings and contextualization of the risk communication strategy and lessons learned from the practitioner's point of view, KV supervised the conduction of the study and provided input in the interpretation of results and write up of the manuscript. All authors read and approved the final manuscript.

\section{Acknowledgments}

We acknowledge funding support from the U.S. Centers for Disease Control and Prevention (CDC) supplement to grant number 5P01TP000307-05 
Preparedness and Emergency Response Research Center and grant 1U90TP000147-05 Preparedness and Emergency Response Learning Center. The content of this publication as well as the views and discussions expressed in these paper are solely those of the authors and do not necessarily represent the views of any partner organizations, the CDC or the U.S. Department of Health and Human Services nor does mention of trade names, commercial practices, or organizations imply endorsement by the U.S. Government.

\section{Author details}

'Department of Biostatistics and Division of Policy Translation and Leadership Development, Harvard T.H. Chan School of Public Health, 401 Park Drive, Boston 02115, MA, USA. ²Department of Health Systems Administration and Population Health, Georgetown University, 3700 Reservoir Road, NW Room 236, Washington, DC 20057-1107, USA. "3West Virginia Bureau for Public Health, 350 Capitol Street, Charleston, WV 25301, USA. ${ }^{4}$ Kanawha-Charleston Health Department, 108 Lee Street East, Charleston, WV 25301, USA. ${ }^{5}$ Department of Social and Behavioral Sciences, Harvard T.H. Chan School of Public Health, 677 Huntington Avenue, Boston 02115, MA, USA.

\section{Received: 17 March 2015 Accepted: 10 August 2015}

\section{Published online: 19 August 2015}

\section{References}

1. Shade CP, Wright N, Gupta R, Latif DA, Jha A, Robinson J. Self-reported household impacts of large-scale chemical contamination of the public water supply, charleston, West Virginia. USA PloS One. 2015;10(5):e0126744.

2. McGuire, M. J.; Rosen, J.; Whelton, A. J.; Suffet, I. H. An Unwanted Licorice Odor in a West Virginia Water Supply. J. Am. Water Works Assoc. 2014; 72-82. Available at: https://www.researchgate.net/profile/Andrew_Whelton/ publication/269953242_An_unwanted_licorice_odor_in_a_West_Virginia_ water_supply/links/551 b53560cf251c35b5098b5.pdf [accessed 23 June 2015]

3. Ward K Jr. 300 K lack water in Southern W.Va. The Charleston Gazette, online edition (10 January 2014). Available at: http:/wwww.wvgazette.com/ News/201401100028 [Accessed 24 February 2015].

4. Gutman D. Freedom call to DEP: "Dike is containing the material." The Charleston Gazette, online edition (1 February 2014). Available at: http:// www.wvgazette.com/News/201402010015 [Accessed 24 February 2015].

5. Governor Tomblin Declares State of Emergency for Nine Counties. State of West Virginia Governor Earl Ray Tomblin's Office, Charleston, WV, January 9 2014. Available at: http://www.governor.wv.gov/media/pressreleases/2014/ Pages/governor-tomblin-declares-state-of-emergency-in-9-counties.aspx [Accessed 23 June 2015]

6. Stoto MA., Piltch-Loeb R., Savoia E. The Public Health System Response to the 2014 West Virginia Water Crisis. January 9 2015. Available at: https:// cdn1.sph.harvard.edu/wp-content/uploads/sites/1609/2015/01/WV-watercrisis-report-final.pdf [Accessed 23 June 2015]

7. Safety Data Sheet Crude MCHM. 2011Available at: http://ws.eastman.com/ ProductCatalogApps/PageControllers/MSDS_PC.aspx?Product=71014291 [Accessed 23 June 2015]

8. Lan J, Hu M, Gao C, Alshawabkeh A, Gu AZ. Toxicity assessment of 4-Methyl-1-cyclohexanemethanol and its metabolites in response to a recent chemical spill in West Virginia, USA. Environ Sci Technol. 2015;49(10):6284-93.

9. West Virginia American Water (WVAW). How to Flush your Plumbing System and How to Flush Plumbing Faucets and Appliances; Charleston, WV, January 2014. Available at http://www.amwater.com/files/WV\%20\%20How\%20to\%20flush.pdf [Accessed on 23 June 2015]

10. Cantrell N. West Virginia's chemical industry. West Virginia Historical Society. Volume XVIII, No 2 April 2004. Available at: http://www.wvculture.org/ history/wvhs1821.pdf [Accessed on 23 June 2015]

11. Viswanath K, Ramanadhan SR, Kontos EZ. Macrosocial determinants of population health. In: Galea S, editor. Mass media and population health: a macrosocial view. New York: Springer; 2007. p. 275-94.

12. Glik D. Risk communication for public health emergencies. Annu Rev Publ Health. 2007;28:33-54.

13. Cairns G, De Andrade M, MacDonald L. Reputation, relationships, risk communication, and the role of trust in the prevention and control of communicable disease: a review. J Health Commun Int Perspect. 2013;18(12):1550-65.
14. Blanchard JC, Haywood Y, Stein BD, Tanielian TL, Stoto M, Lurie N. In their own words: lessons learned from those exposed to anthrax. Am J Public Health. 2005;95:489-95.

15. Elledge BL, Brand M, Regens JL, Boatright DT. Implications of public understanding of avian influenza for fostering effective risk communication. Health Promot Pract. 2008;9(4):54-9.

16. Morrison G, Yardley L. What infection control measures will people carry out to reduce transmission of pandemic influenza? A focus group study. BMC Public Health. 2009;9(1):258.

17. Charles DiSogra, Curtiss Cobb, Elisa Chan, J. Michael Dennis. Calibrating Non-Probability Internet Samples with Probability Samples Using Early Adopter Characteristics. Knowledge Networks, 2100 Geng Road, Suite 210, Palo Alto, CA 94303. Section of Survey Research methods. Joint Statistical Meetings. Available at: http://www.knowledgenetworks.com/ganp/docs/ JSM-2011-Calibration-Paper_DiSogra.pdf [Accessed 22 February 2015]

18. Galarce EM, Viswanath K. Crisis communication: an inequalities perspective on the 2010 Boston water crisis. Disaster Med Public Health Prep. 2012;6(4):349-56.

19. Gallup. Few Americans Want More Gov't Regulation of Business Available at: http://www.gallup.com/poll/176015/few-americans-gov-regulationbusiness.aspx?utm_source=trust\%20in\%20government\&utm_medium= search\&utm_campaign=tiles [Accessed on 22 February 2015]

20. Luo J, Cong Z, Liang D. Number of warning information sources and decision making during tornadoes. Am J Prev Med. 2015;48(3):334-7.

21. Aburto NJ, Pevzner E, Lopez-Ridaura R, Rojas R, Lopez-Gatell H, Lazcano E, et al. Knowledge and adoption of community mitigation efforts in Mexico during the 2009 H1N1 pandemic. Am J Prev Med. 2010;39(5):395-402.

22. Viswanath K, Finnegan JR. The knowledge gap hypothesis: twenty-five years later. In: Burleson B, editor. Communication yearbook 19. Thousand Oaks (CA): SAGE Publications; 1996. p. 187-227.

23. Taylor-Clark K, Viswanath K, Blendon R. Communication inequalities during Public Health disasters: Katrina's wake. Health Commun. 2010;14(3):221-9.

24. Blendon RJ, Benson JM, Desroches CM, Weldon KJ. Using opinion surveys to track the public's response to a bioterrorist attack. J Health Commun. 2003;14 Suppl 1:83-92. 148-151.

25. Pearce JM, Rubin GJ, Amlot R, Wessely S, Rogers MB. Communicating public health advice following a chemical spill. Disaster Med Public Health Prep. 2013;7(1):65-74.

26. Meredith LS, Eisenman DP, Rhodes H, Ryan G, Long A. Trust influences response to public health messages during a bioterrorist event. J Health Commun. 2007:12(3):217-32.

27. Quinn SC, Parmer J, Freimuth VS, Hilyard KM, Musa D, Kim KH, et al. Exploring communication, trust in government, and vaccination intention later in the $2009 \mathrm{H} 1 \mathrm{~N} 1$ pandemic: results of a national survey. Biosecur Bioterror. 2013;11(2):96-106.

28. Reynolds BJ. Building trust through social media. CDC's experience during the H1N1 influenza response. Mark Health Serv. 2010;30(2):18-21.

29. Prati G, Pietrantoni L, Zani B. Compliance with recommendations for pandemic influenza H1N1 2009: the role of trust and personal beliefs. Health Educ Res. 2011;26(5):761-9.

30. Freimuth VS, Musa D, Hilyard K, Quinn SC, Kim K, et al. Trust during the early stages of the 2009 H1N1 pandemic. J Health Commun. 2014;19(3):321-39.

\section{Submit your next manuscript to BioMed Central and take full advantage of:}

- Convenient online submission

- Thorough peer review

- No space constraints or color figure charges

- Immediate publication on acceptance

- Inclusion in PubMed, CAS, Scopus and Google Scholar

- Research which is freely available for redistribution 